\title{
Pattern of Adverse Drug Reactions Reported with Use of Antimicrobial Drugs in a Tertiary Care Hospital
}

\author{
Shraddha Milind Pore' ${ }^{1}$ Shreyas Ramchandra Burute ${ }^{2 *}$, Amar Dinkar Shinde ${ }^{1}$, Sunita Jaiprakash Ramanand ${ }^{1}$ \\ 'Department of Pharmacology, Government Medical College, Miraj, Maharashtra, INDIA. \\ ${ }^{2}$ Adverse Drug Reaction Monitoring Centre, Government Medical College, Miraj, Maharashtra, INDIA.
}

\begin{abstract}
Objective: The present study was undertaken to evaluate pattern, commonly implicated drugs, causality and severity of adverse drug reactions (ADRs) reported with antimicrobial drugs. Methodology: Antimicrobial drug related Individual Case Safety Reports (ICSRs) reported at Adverse Drug Reaction Monitoring Centre from July 2015 to June 2016 were analyzed to evaluate pattern, implicated drugs, causality and severity of ADRs. Descriptive statistics was used. Results: Ninety (59.6\%) out of 151 ICSRs belonged to age group 21-40 years. Out of 151 ICSRs 73 (48.34\%) were related to antibacterials. Maculopapular rash and Chills with rigor/fever were observed in $22.37 \%$ and $19.58 \%$ cases respectively. Five drugs/fixed dose combination (FDCs) contributed to $62.23 \%$ (89/143) of ADRs. FDC of tenofovir DF+lamivudine+efavirenz was associated with most $(21.67 \%)$ ADRs followed by ceftriaxone (14.68\%). Causality was possible, probable and certain for $50.99 \%, 17.88 \%$ and $25.82 \%$ of ICSRs respectively. Severity was moderate for $73.42 \%$ and mild for $25.16 \%$ of ADRs. Conclusion: Beta-lactam antibacterials, second line anti-tubercular drugs and antiretrovirals drugs were responsible for most ADRs. Maculopapular rash was most common
\end{abstract}

with antiretroviral drugs and chills/rigors with IV Ceftriaxone. Most ADRs were of moderate severity.

Key words: Drug related side effects, Antibacterial drugs, Antiretroviral drugs, Antitubercular drugs, Drug eruptions.

Key message: Antimicrobials are an important cause of adverse drug reactions. Beta-lactam antibacterials, second line anti-tubercular drugs and antiretroviral drugs are more commonly implicated in causation of ADRs. Majority of ADRs are of moderate severity and skin is most commonly affected organ.

\section{Correspondence}

Dr. Shreyas Ramchandra Burute, 171, 'Saili' Bunglow, Ramaudhyan Phase II Pandharpur Road, Miraj. District Sangli, Maharashtra, INDIA.

Phone: +919422602624

Email: shreyas.burute@gmail.com

DOI: 10.5530/jyp.2018.10.47

\section{INTRODUCTION}

An Adverse Drug Reaction (ADR) is defined as "any response to a drug which is noxious and unintended and which occurs at doses normally used in man for prophylaxis, diagnosis or therapy of disease or for modification of physiological function." ${ }^{1}$ ADRs appear to be common occurrence especially in hospitalized patients. A recent systematic review by Patel et al shows that median incidence of ADR that led to hospitalization and ADRs that developed during hospitalization was $2.85 \%$ and $6.34 \%$ respectively. ${ }^{2}$ The burden of ADRs is high and accounts for considerable morbidity, mortality and extra cost. ${ }^{3}$

Pharmacovigilance Programme of India (PvPI) initiated in July 2010; plays vital role in improving safety of medicines in Indian population. Under PvPI, various regional ADR monitoring centers (AMCs) have been established at various medical institutions throughout the country. ${ }^{4}$ Number of drug utilization studies show that antimicrobials constitute one of the commonly used groups of drugs. ${ }^{5,6}$ Various studies examining pattern of adverse drug reactions in hospitalized patients indicate that antimicrobials account for substantial proportion of adverse drug reactions. ${ }^{7,8}$ Utilization of antimicrobials is expected to vary from region to region according to services provided and availability of antimicrobials. ${ }^{9,10}$ Further the treatment guidelines for chronic infections like tuberculosis and human immunodeficiency virus (HIV) warrant the use of multiple antimicrobials together. ${ }^{11,12}$ This along with poly pharmacy to treat associated co-morbidities, the varying immune status of the patient, the nature of the disease itself and the limitations imposed by the availability of services and resources makes it particularly challenging to assess the causality and attribute an adverse event to these particular group of drugs. All the above factors may influence the ADR pattern for antimicrobials in a region. It thus becomes imperative to study the pattern and severity of ADRs and find the most common agents causing them in a given region. Data obtained from such observational studies is expected to help healthcare professionals to use antimicrobials safely in future.

Thus the present study was undertaken with the aim of evaluating pattern, commonly implicated drugs, causality and severity of ADRs reported with use of antimicrobial drugs.

\section{MATERIALS AND METHODS}

This study analyzed all antimicrobial drug related individual case safety reports (ICSRs) reported at AMC, Government Medical College, Miraj, during the period of July 2015 to June 2016. The ICSRs came through spontaneous reporting as well as active surveillance by Pharmacovigilance Associate (PvA), who regularly visited the wards and OPDs of the hospitals affiliated to the medical college.

The ICSRs were analyzed by pharmacovigilance team comprising of pharmacologists, clinician and PvA. The ICSRs were categorized according to Common Terminology Criteria for Adverse Events(CTCAE version 4.0$)^{13}$ and Causality assessment of ADRs was done by using World Health Organization-Uppsala Monitoring Centre (WHO-UMC)

This is an open access article distributed under the terms of the Creative Commons Attribution-NonCommercial-ShareAlike 4.0 License, which allows others to remix, tweak, and build upon the work non-commercially, as long as the author is credited and the new creations are licensed under the identical terms. 
Pore et al.: Adverse drug reaction pattern to Antimicrobials

causality assessment scale as certain, probable, possible, unlikely, unclassified and unassessable /unclassifiable. ${ }^{14}$ The severity of ADRs was assessed by modified Hartwig and Siegel scale. ${ }^{15}$ Those ADRs whose causality was assessed as unlikely, unclassified and unassessable were not included in further analysis. The study was approved by Institutional Ethics Committee.

Statistical analysis: Descriptive statistics was used to analyze the data and values are expressed in numbers and percentages.

\section{RESULTS}

During the study period a total of 258 ICSRs were received at AMC, out of these 151 (58.52\%) belonged to antimicrobial drugs. Majority [90 (59.60\%)] of the 151 ICSRs belonged to the age group ranging from 21 to 40 years, whereas $6.62 \%$ belonged to those above 60 years [Table 1]. More ICSRs belonged to females $(55.62 \%)$ as compared to males (44.37\%) [Table 1].

When ICSRs were categorized according to CTCAE version 4.0 [Table 2], it was seen that majority (41.05\%) of ICSRs were related to skin and subcutaneous disorders followed by general disorders and administration site conditions (26.49\%).These ICSRs along with ICSRs related to blood and lymphatic system disorder (10.59\%), psychiatric disorders $(7.28 \%)$ and ear and labyrinth disorders (3.31\%) together constituted $88.72 \%$ of 151 ICSRs and were the top five groups of organ systems involved.

Causality assessment of ICSRs [Table 3] showed that, only $25.82 \%$ ICSRs could be assessed as certain and $17.88 \%$ could be assessed as probable. Most (50.99\%) ICSRs were assessed as possible. Majority (37/73) of the ICSRs to antibacterial drugs could be assessed as certain, whereas majority of ICSRs to Antitubercular drugs (17/23) and Antiretroviral drugs (40/52) were assessed as possible. Also out of the eight (5.29\%) ICSRs assessed as unassessible majority were antiretroviral (5/8). These eight ICSRs were not included in further analysis. No ICSRs could be classified as unlikely and conditional/unclassified.

Table 4 shows that maculopapular rash was the most common (32/143, 22.37\%) ADR encountered with antimicrobial use, the main culprits being antiretroviral drugs $(24 / 143,16.78 \%)$. The second most common ADRs were chills with rigors/fever caused mostly by antibacterial drugs $(27 / 143,18.88 \%)$ and particularly by ceftriaxone $(n=14)$ and a fixed dose combination (FDC) of amoxicillin+ potassium clavulanate $(n=10)$. More than fifty percent cases of pruritis were observed with ciprofloxacin $(\mathrm{n}=7)$. Most ADRs to antibacterial drugs were hypersensitivity reactions (pruritis, urticaria, allergic reactions, anaphylaxis, bronchospasm, injection site reactions) [Table 4]. There were ten cases of psychosis associated with cycloserine $(n=5)$ and efavirenz $(n=5)$ (results not shown). The suspected drug was withheld in all cases. The causality assessment was possible or probable in nine cases while it was unassessible in one case where psychosis appeared to be related to hyperglycemic episode. Anemia was observed as the second most common ADR to antiretroviral drugs [Table 4]. All twelve cases were related to zidovudine [Table 5]. Severe anemia (hemoglobin $<8 \mathrm{gm} \%$ ) was observed in seven patients. There was wide variation in latent period with six cases being observed before one year, two after one year and few after two or three years (not shown in Table). Other ADRs such as deafness (associated with kanamycin), hypersensitivity reactions, injection site reactions, gastritis (associated with para-amino salicylic acid), gynecomastia (associated with ethionamide), hepatitis due to first line antitubercular drugs, and toxic epidermal necrolysis with ciprofloxacin/metronidazole were also observed in this study (not shown in Table 4).

Three fourth (109/143) of ADRs were caused by the top ten antimicrobials as depicted in Table 5 . Out of these, $81.65 \%$ (89/109) were caused by five drugs [Table 5]. FDC of tenofovir DF+lamivudine+efavirenz was
Table 1: Age and gender distribution of Individual Case Safety Reports (ICSRs) to antimicrobials $(n=151)$

\begin{tabular}{ccc}
\hline Characteristic & Value & Percentage (\%) \\
\hline Age & & \\
Below 20 years & 24 & 15.89 \\
21 to 40 years & 90 & 59.60 \\
41 to 60 years & 27 & 17.88 \\
Above 60 years & 10 & 6.62 \\
Gender & & \\
Males & 67 & 44.37 \\
Females & 84 & 55.62 \\
\hline
\end{tabular}

Table 2: Categorization of Individual Case Safety Reports (ICSRs) according to Common Terminology Criteria for Adverse Events (CTCAE version 4.0) $(n=151)$

\begin{tabular}{ccc}
\hline Organ system & Number of ICSRs & Percentage (\%) \\
\hline $\begin{array}{c}\text { Skin and subcutaneous tissue } \\
\text { disorders }\end{array}$ & 65 & 41.05 \\
$\begin{array}{c}\text { General disorders and } \\
\text { administration site conditions } \\
\text { Blood and lymphatic system } \\
\text { disorder }\end{array}$ & 40 & 26.49 \\
$\quad \begin{array}{c}\text { Psychiatric disorders } \\
\text { Ear and labryninth disorder }\end{array}$ & 16 & 10.59 \\
$\begin{array}{c}\text { Nervous system disorders } \\
\text { Musculoskeletal and connective } \\
\text { tissue disorders }\end{array}$ & 5 & 7.28 \\
$\begin{array}{c}\text { Gastrointestinal disorder } \\
\text { Reproductive system and breast } \\
\text { disorders }\end{array}$ & 2 & 3.31 \\
$\begin{array}{c}\text { Respiratory, thoracic and } \\
\text { mediastinal disorders }\end{array}$ & 2 & 1.98 \\
Endocrine disorder & 2 & 1.32 \\
$\begin{array}{c}\text { Hepatobiliary disorders } \\
\text { (1) }\end{array}$ & 2 & 1.32 \\
\hline
\end{tabular}

associated with most (21.67\%) of observed ADRs followed by ceftriaxone (14.68\%).

When the ADRs were assessed for severity by using modified Hartwig and Siegel's severity scale, $73.42 \%(105 / 143)$ of the ADRs were assessed to be moderately severe [Table 6]. Out of these $54.54 \%$ of ADRs required the treatment to be discontinued/withheld/changed and/or required treatment for the ADR but did not extend the hospital stay of patients (moderate level 3 severity). Whereas hospital stay was extended in $17.48 \%$ cases (moderate level 4 severity) .One fourth of the ADRs were assessed to be mild (level 2) severity and didn't require any treatment other than discontinuation/changing/withholding the suspected drug. One fatal case of hepatitis (Severity level 7) was associated with FDC of isoniazid+ pyrazinamide+ rifampicin.

\section{DISCUSSION}

Antimicrobials are an important cause of ADRs in hospitalized patients. ${ }^{16}$ The present study analyzed 151 ADRs to antimicrobials received by AMC during one year period. The demographic data indicated that female gender and the age-group of 21-40 years were most commonly affected. Our results are supported by previous studies. ${ }^{17,18}$ The percentage 
Table 3: Causality assessment of Individual Case Safety Reports (ICSRs) to antimicrobials by WHO-UMC scale $(n=151)$

\begin{tabular}{cccccc}
\hline Antimicrobial class & Certain $\mathbf{n}(\%)$ & Probable $\mathbf{n}(\%)$ & $\begin{array}{c}\text { Possible } \\
\mathbf{n}(\%)\end{array}$ & Unassessable $\mathbf{n}(\%)$ & $\begin{array}{c}\text { Total } \\
\mathbf{n}(\%)\end{array}$ \\
\hline Antibacterial & $37(24.50)$ & $16(10.59)$ & $19(12.58)$ & $1(0.66)$ & $73(48.34)$ \\
Antitubercular & $1(0.66)$ & $3(1.98)$ & $17(11.25)$ & $2(1.32)$ & $23(15.23)$ \\
Antiretroviral & $1(0.66)$ & $6(3.97)$ & $40(26.49)$ & $5(3.31)$ & $52(34.43)$ \\
Antifungal & $0(0)$ & $2(1.32)$ & $1(0.66)$ & $0(0)$ & $3(1.91)$ \\
Total & $39(25.82)$ & $27(17.88)$ & $77(50.99)$ & $8(5.29)$ & $151(100)$ \\
\hline
\end{tabular}

Table 4: Frequency of different Adverse Drug Reactions encountered with antimicrobials ( $n=143 *)$

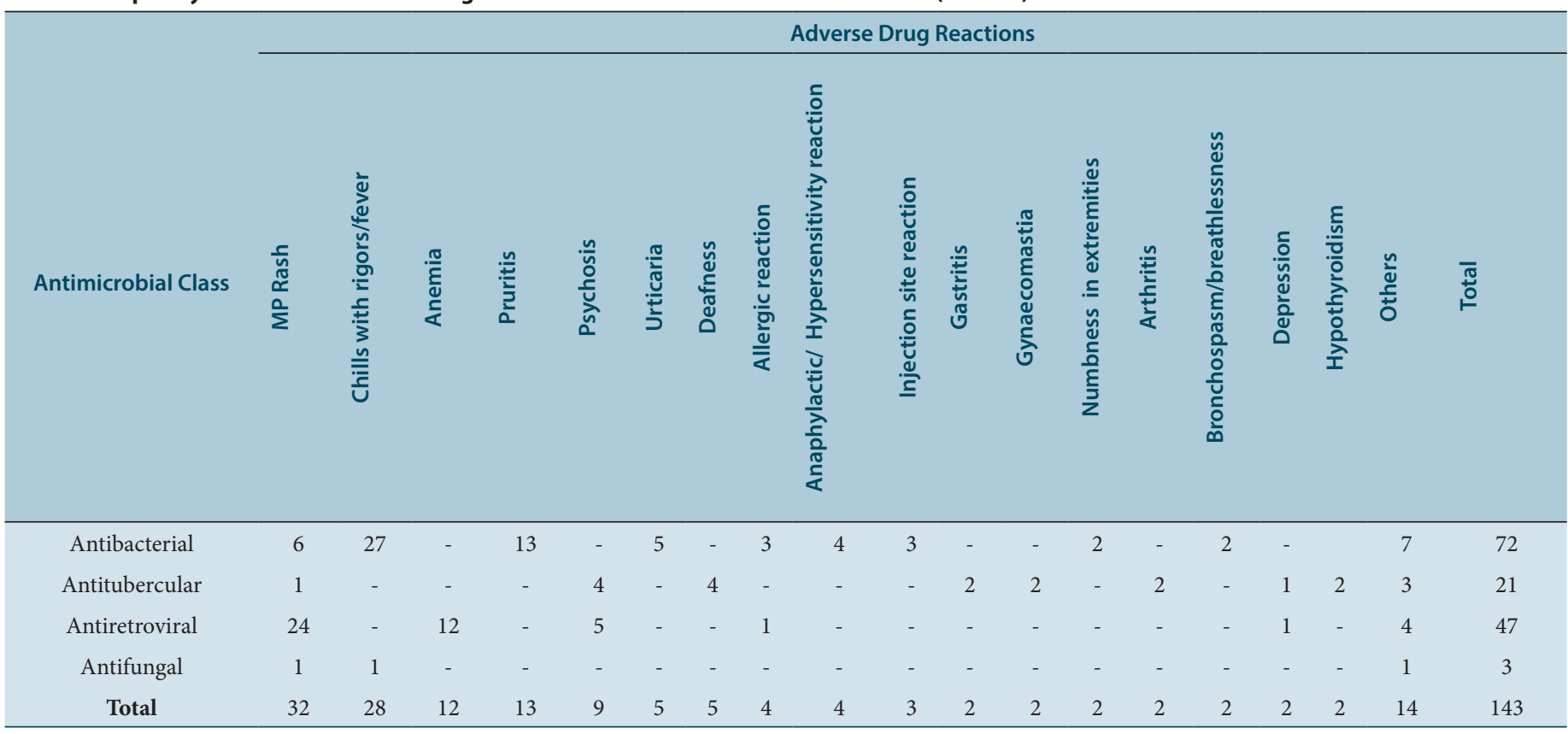

MP rash-Maculopapular rash. ${ }^{\star}$ Only ICSRs with causality assessment possible and above were included.

Table 5: The top ten antimicrobials associated with ADRs and most frequent ADRs observed with them ( $\left.n=143^{*}\right)$

\begin{tabular}{cccc}
\hline Antimicrobials & Number of ADRs & $\begin{array}{c}\text { Percentage } \\
(\%)\end{array}$ & Most frequent ADRs observed \\
\hline FDC of Tenofovir DF + Lamivudine+Efavirenz & 31 & 21.67 & MP rash, Psychosis, depression \\
Ceftriaxone & 21 & 14.68 & Chills with rigors, Hypersensitivity reaction, Urticaria \\
Chills with fever & Pruritus \\
Amoxicillin+Pot. Clavulanate & 13 & 9.09 & Anemia \\
Ciprofloxacin & 12 & 8.39 & Deafness \\
FDC of Zidovudine+Lamivudine +Nevirapine & 12 & 8.39 & 3.49 \\
Kanamycin & 5 & 2.79 & Hypothyroidism, Gynaecomastia \\
Cycloserine & 4 & 2.79 & Psychosis \\
Vancomycin & 4 & 2.79 & Pruritus \\
Clindamycin & 4 & 2.09 & Numbness in extremity \\
\hline
\end{tabular}

ADRs- Adverse Drug Reactions. ${ }^{*}$ Only ICSRs with causality assessment possible and above were included. 
Pore et al.: Adverse drug reaction pattern to Antimicrobials

\begin{tabular}{|c|c|c|c|c|c|c|c|c|c|}
\hline \multirow{2}{*}{$\begin{array}{c}\text { Severity levels } \\
\text { Antimicrobial class }\end{array}$} & \multicolumn{2}{|c|}{ Mild } & \multicolumn{3}{|c|}{ Moderate } & \multicolumn{3}{|c|}{ Severe } & \multirow{2}{*}{$\begin{array}{c}\text { Total no. of } \\
\text { reactions } \\
\text { n (\%) }\end{array}$} \\
\hline & $\begin{array}{l}\text { level } 1 \\
\text { n (\%) }\end{array}$ & $\begin{array}{l}\text { level } 2 \\
\text { n (\%) }\end{array}$ & $\begin{array}{l}\text { level } 3 \\
\text { n (\%) }\end{array}$ & $\begin{array}{c}\text { level } 4 a \\
\text { n (\%) }\end{array}$ & $\begin{array}{c}\text { level 4b } \\
\text { n (\%) }\end{array}$ & $\begin{array}{l}\text { level } 5 \\
\mathrm{n}(\%)\end{array}$ & $\begin{array}{l}\text { level } 6 \\
\mathrm{n}(\%)\end{array}$ & $\begin{array}{l}\text { level } 7 \\
\mathrm{n}(\%)\end{array}$ & \\
\hline Antibacterial & & $35(24.47)$ & $29(20.27)$ & $5(3.49)$ & $2(1.39)$ & $1(0.69)$ & & & $72(50.34)$ \\
\hline Antitubercular & & & 13(9.09) & $7(4.89)$ & & & & $1(0.69)$ & $21(14.68)$ \\
\hline Antiretroviral & $1(0.69)$ & & $33(23.07)$ & 13(9.09) & & & & & $47(32.86)$ \\
\hline Antifungal & & & $3(2.09)$ & & & & & & $3(2.09)$ \\
\hline Total & $1(0.69)$ & $35(24.47)$ & $78(54.54)$ & $25(17.48)$ & $2(1.39)$ & $1(0.69)$ & $0(0)$ & $1(0.69)$ & $143(100)$ \\
\hline
\end{tabular}

ADRs: Adverse Drug Reactions. ${ }^{\star}$ Only ICSRs with causality assessment possible and above were included.

of ADRs in elderly observed in the present study is $6.62 \%$. This is less as compared to previous studies which involved intensive monitoring. ${ }^{19}$

Categorization according to CTCAE showed skin to be most commonly affected organ system with maculopapular rash being observed in $22.37 \%$ of patients followed by pruritis and urticaria. Our findings are supported by various studies. ${ }^{17,18,20} \mathrm{~A}$ systematic review of cutaneous ADRs in Indian population involving 18 prospective studies showed antimicrobials as common causes of ADRs especially maculopapular rash. ${ }^{21}$ Maculopapular rash was most commonly associated with antiretroviral drugs. Most of these drugs were given as FDC. As any drug in FDC has potential to cause rashes plus HIV infection itself could cause rash, the causality assessment was possible as per WHO-UMC scale. These findings are supported by previous studies which indicate that antiretroviral drugs commonly lead to drug eruptions. ${ }^{22,23}$

In the present study ceftriaxone was most common antibacterial associated with adverse reactions $\{21 / 151(14.68 \%)\}$, especially hypersensitivity reactions such as rigors, bronchospasm, urticaria etc. The reason could be that it is the most commonly used antibacterial in our setting. In most cases, rigors appeared within few minutes of intramuscular or intravenous injection of these antimicrobials allowing causality to be assessed as certain. The prescribing information of ceftriaxone clearly mentions chills as a symptom of hypersensitivity. ${ }^{24}$ Iranian Pharmacovigilance Centre (IPC), in a ten-year review, reported that ceftriaxone was most frequently implicated drug in adverse events reported to IPC and was associated with cutaneous reactions, plus serious adverse events such as anaphylactic and anaphylactoid reactions, deaths etc. ${ }^{25}$ Rigors were also reported in $1.56 \%$ cases. $^{25}$ The common occurrence of rigors with ceftriaxone in the present study could be related to rapid intravenous injection because rather than random reactions these were observed in clusters. Rapid intravenous injection is one of the important risk factors for adverse events with ceftriaxone so much so that it is recommended that the dose should be given slowly over a period of at least thirty minutes. ${ }^{25}$ The AMC personnel discussed the matter with the concerned health care professionals which led to decrease in such reactions afterwards.

The causality assessment was particularly challenging for zidovudine related anemia, since it was difficult to rule out other causes of anemia with the available data. As a result, out of sixteen ICSRs, we could assess causality only as 'possible' in twelve cases and four cases were 'unassessible. In a previous study, most cases of anemia associated with zidovudine were detected within 4-6 weeks ${ }^{26}$ or up to six months and almost all were detected up to twelve months ${ }^{27}$ As opposed to this the present study showed anemia after one year in six cases. The reason could be that although routine monitoring of hemoglobin level is advised to the patients, many patients do not get it done regularly (this was evident from patients records) as a result anemia is detected very late. In all cases zidovudine was stopped and patients with severe anemia received blood transfusion.

Second-line anti-TB drugs cause substantial ADRs and often require change/cessation of treatment. ${ }^{28}$ There were four cases $(2.79 \%)$ of psychosis associated with cycloserine and five cases (3.49\%) of deafness associated with kanamycin in present study. The drugs were withheld in all cases and treatment changed.

The severity analysis by modified Hartwig-Siegel scale showed that most of the reactions were mild $(25.16 \%)$ to moderate $(73.41 \%)$. Hospital stay was extended in $17.48 \%$ cases (moderate level 4 severity) while $1.39 \%$ was serious as they required intensive medical care or were fatal $(0.69 \%)$. Similar results have been obtained by previous studies. ${ }^{18,29}$

There are some limitations of the present study. Firstly in any voluntary reporting system, there is possibility of under-reporting. Secondly, most of the ADRs in the study came from teaching hospital where AMC is functioning. So the drugs commonly associated with ADRs and pattern of ADRs primarily reflects drug use in our setting.

\section{CONCLUSION}

Antimicrobials were commonly associated with dermatological reactions followed by rigors after parenteral administration and anemia. Most of the adverse reactions were attributed to ceftriaxone, amoxicillin-clavulanic acid, ciprofloxacin, antiretroviral drugs and drugs used for multidrug resistant tuberculosis. Most of the reactions were of mild to moderate severity.

\section{ACKNOWLEDGEMENT}

We are grateful to National Coordinating Centre, Pharmacovigilance Programme of India, (NCC, PvPI) Ghaziabad, Ministry of Health and Family Welfare for providing necessary technical support through regional Adverse Drug Reaction Monitoring Centre (AMC) functioning at our Institute.

\section{CONFLICT OF INTEREST}

The authors declare no conflict of interest.

\section{ABBREVIATIONS}

ADR: Adverse Drug reaction; ICSR: individual Case Safety Report; AMC: Adverse drug reaction Monitoring Centre; FDC: Fixed Dose Combination; Tenofovir DF: tenofovir disoproxil fumarate; PvPI: Pharmacovigilance Programme of India; HIV: Human immunodeficiency Virus; PvA: Pharmacovigilance Associate; CTCAE: Common Terminology Criteria for Adverse Events; WHO-UMC: World Health Organization- Uppsala monitoring centre; IPC: Iranianian Pharmacovigilance centre. 


\section{REFERENCES}

1. World Health Organization. Definitions. [Internet]. [cited2017Nov3]. Available from: www.who.int/medicines/areas/quality_safety/safety_efficacy/.../definitions. pdf [Last accessed on 10/02/2018]

2. Patel TK, Patel PB. Incidence of adverse drug reactions in Indian hospitals: A systematic review of prospective studies. Curr Drug Saf. 2016;11(2):128-36.

3. Pirmohamed M, James S, Meakin S, Green C, Scott AK, Walley TJ, et al. Adverse drug reactions as cause of admission to hospital: prospective analysis of 18820 patients. BMJ. 2004;329(7456):15-9.

4. Pharmacovigilance Programme of India.[Internet]. [cited 2017 Nov 27].Available from: www.ipc.gov.in/PvPl/ pv_home.html [Last accessed on 12/02/2018].

5. Mittal N, Mittal R, Singh I, Shafiq N, Malhotra S. Drug utilisation study in a tertiary care center: Recommendations for improving hospital drug dispensing policies. Indian J Pharm Sci. 2014;76(4):308-14

6. Thiruthopu NS, Mateti UV, Bairi R, Sivva D, Martha S. Drug utilization pattern in South Indian pediatric population: A prospective study. Perspect Clin Res. 2014;5(4):178-83.

7. Peter JV, Varghese GH, Alexander H, Tom NR, Swethalekshmi V, Truman C, et al. Patterns of Adverse Drug Reaction in the Medical Wards of a Teaching Hospital: A Prospective Observational Cohort Study. Curr Drug Saf. 2016;11(2):164-71.

8. Digra KK, Pandita A, Saini GS, Bharti R. Pattern of adverse drug reactions in children attending the department of pediatrics in a tertiary care center: A prospective observational tudy. Clin Med Insights Pediatr. 2015;9:73-8.

9. Hedamba R, Doshi C, Darji NH, Patel B, Kumari, Trivedi HR. Drug utilization pattern of antimicrobial drugs in intensive care unit of a tertiary care hospital attached with a medical college. Int J Basic Clin Pharmacol. 2016;5(1):169-72.

10. Benjamin B, KumarBS, Udaykumar P, Swamy NVB. Comparative drug utilization of antimicrobial agents in medical and respiratory intensive care units of a tertiary care teaching hospital in south india. Indian J Pharm Practice. 2016;9(2):123-9.

11. Ministry of Health and Family Welfare-Government of India. Central Tuberculosis Division; Directorate of Health Services. Guidelines: Central TB division technical and operational guidelines for TB control in India 2016. Available from: https:// tbcindia.gov.in/index1.php?lang $=1$ andlevel=1 andsublinkid $=4571$ andlid $=3176$ [Last accessed on 10/02/2018]

12. Ministry of Health and Family Welfare, Government of India. Department of AIDs control, National AIDS Control Organization. Antiretroviral therapy guidelines for HIV infected adults and adolescents including post exposure prophylaxis. Available from: http://naco.gov.in/sites/default/files/Antiretroviral\%20Therapy\% 20 Guidelines $\% 2$ for $\% 20$ HIV-Infected \% 20Adults \% 20and \% 20Adolescents\%20May\%202013\%281\%29_0.pdf [Last accessed on 10/02/2018].

13. US Department of Health and Human Services. National Institute of Health; National Cancer Institute. Common Terminology Criteria for Adverse Events (CTCAE) ver. 4.0[Internet]. 28 May 2009 (ver. 4.03: 14 June 2010). Available from: http://evs.nci.nih.gov/ftp1/CTCAE/CTCAE_4.03_2010-06-14_ QuickReference_5x7.pdf [Last accessed on 27/07/2017].

14. World Health Organization. The use of the WHO-UMC system for standardized case causality assessment. Available at: http://www.WHO-UMC.org/ graphics/ 4409.pdf [Last accessed on 27/11/2017].

15. Hartwig SC, Siegel J, Schneider PJ. Preventability and severity assessment in reporting adverse drug reactions. Am J Hosp Pharm. 1992;49(9):2229-32.

16. Singh H, Dulhani N, Kumar BN, Singh P, Tewari P, Nayak K. A pharmacovigilance study in medicine department of tertiary care hospital in Chhattisgarh (Jagdalpur), India. J Young Pharm. 2010;2(1):95-100.

17. Nagaiah BH, Patil SB, Vahila N, Rao YV, Raikar SR, Sajid M. Analysis of adverse drug reactions of antimicrobial agents reported to ADR monitoring centre of a rural tertiary care teaching hospital. Int J Basic Clin Pharmacol. 2017;6(5):1151-4.

18. Jayanthi CR, Chaithra KN, Reddy NS. A profile of adverse drug reactions to antimicrobial agents at a tertiary care hospital. Indian J Pharm Pharmacol. 2017;4(1):16-21.

19. Kamejaliya DZ, Kapadia JD, Desai CK, Desai MK. An intensive monitoring of adverse drug reactions among elderly patients hospitalized in medical wards of a tertiary care hospital. J Young Pharm. 2017;9(4):598-604.

20. Tandon VR, Sharma S, Khajuria V, Mhajan V, Gillani Z. Adverse drug reactions profile of antimicrobials: a 3-year experience, from a tertiary care teaching hospital of India. Indian J Med Microbiol. 2015;33(3):393-400.

21. Patel TK, Thakkar SH, Sharma D. Cutaneous adverse drug reactions in Indian population: A systematic review. Indian Dermatol Online J. 2014;5(2):S76-86.

22. Huang XJ, Li HY, Chen DX, Wang XC, Li ZC, Wu YS, et al. Clinical analysis of skin lesions in 796 Chinese HIV-positive patients. Acta Derm Venereol. 2011;91(5):552-6.

23. Pawar MP, Pore SM, Pradhan SN, Burute SR, Bhoi UY, Ramanand SJ. Nevirapine: Most common cause of cutaneous adverse drug reactions in an outpatient department of a tertiary care hospital.J Clin Diagn Res. 2015;9(11):FC17-F20.

24. Food and Drug Administration-USP. Ceftriaxone for Injection. Available from: https://www.accessdata.fda.gov/drugsatfda_docs/label/2014/065169s022lbl. pdf [Last accessed on 06/11/2017].

25. Shalviri G, Yousefian S, Gholami K. Adverse events induced by ceftriaxone: a 10 -year review of reported cases to Iranian pharmacovigilance centre. J Clin Pharm Ther. 2012;37(4):448-51.

26. Rajesh R, Sudha V, Varma DM, Sonika S. Association between medication adherence outcomes and adverse drug reactions to highly active antiretroviral therapy in Indian human immunodeficiency virus positive patients. J Young Pharm. 2012;4(4):250-60.

27. Agarwal D, Chakravarty J, Chaube L, Rai M, Agrawal NR, Sundar S. High incidence of zidovudine induced anaemia in HIV infected patients in eastern India. Indian J Med Res. 2010;132:386-9

28. Patel SV, Nimavat KB, Patel AB, Shringarpure KS, Mehta KG, Shukla LK. Adverse drug reactions in patients put on multi drug resistant tuberculosis (MDR-TB) Treatment in seven districts of central Gujarat. J Young Pharm. 2015;7(4s):425-31.

29. Dhar K, Sinha A, Gaur P, Goel R, Chopra VS, Bajaj U. Pattern of adverse drug reactions to antibiotics commonly prescribed in department of medicine and pediatrics in a tertiary care teaching hospital, Ghaziabad. J Appl Pharm Sci. $2015 ; 5(4): 78-82$

Article History: Submission Date : 25-12-2017 ; Revised Date : 23-01-2018; Acceptance Date : 23-02-2018.

Cite this article: Pore SM, Burute SR, Shinde AD, Ramanand SJ. Pattern of Adverse Drug Reactions Reported with use of Antimicrobial Drugs in a Tertiary Care Hospital. J Young Pharm. 2018;10(2):213-7. 